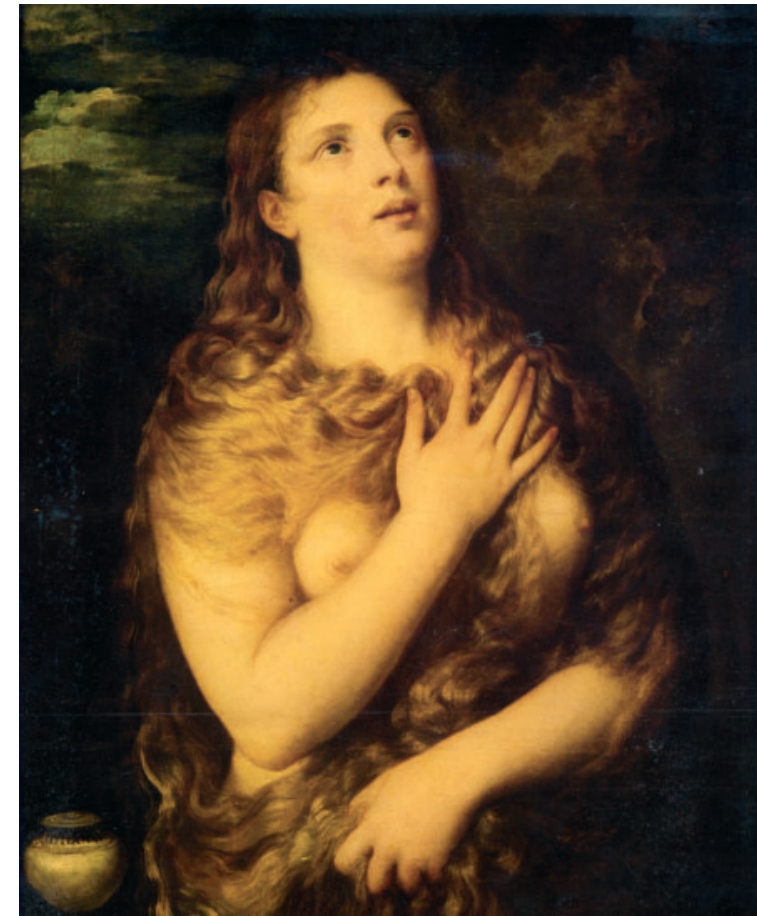

Tizian Magdalena, 1535, Florenz Palazzo Pitti

\section{Vom Auskleiden}

Vielleicht ist es ja doch so, dass man sich erst einmal die Schuhe auszieht und das Jackett auf den Bügel hängt. Wie es weitergeht, hängt sehr von der Tagesform ab. Es gibt auch Varianten. Manche lassen lange die Strümpfe an. Andere zögern mit dem Schmuck. Nicht alles im Leben ist genetisch festge-

Zum Autor: Hans-Joachim Müller

- Studium der Philosophie und

Kunstgeschichte in Freiburg i. Br.

- langjähriger Mitarbeiter im

Feuilleton der ZEIT

- zuletzt Feuilletonchef und

Mitglied der Redaktionsleitung

der Basler Zeitung

- lebt heute als freier Autor

(FAZ, ZEIT, NZZ, art-Magazin) in

Freiburg und in Süditalien. legt. Früher, als man noch Personal hatte, wurde einem beim Aufknöpfen geholfen, und es war dem Kammerfräulein nicht überlassen, ob dies von oben nach unten oder von unten nach oben geschah. So endete der Tag in schöner Ordnung, und nur in ganz seltenen Fällen soll ein Schnürleib am Wandschirm hängengeblieben sein.

Das alles ist lange her. Und längst herrscht Freistil im Boudoir. Und wir wüssten von der Dramaturgie des Entkleidens und vom Tauschhandel der Blicke nicht mehr viel, wenn es nicht schon immer zur Lieblingsbeschäftigung von Malern und Schriftstellern gehört hätte, Frau Venus den Handspiegel zu halten und so tun, als wollte man nicht stören. Dass an ihren Berichten zuweilen eine gewisse Großzügigkeit im Umgang mit den Details zu beklagen scheint, wird man der Schicklichkeit anzulasten haben. Kaum nämlich haben Polly und der junge Genueser das Gemach betreten, da reicht er ihr auch schon ein Glas Wein mit neapolitanischem Biskuit und sieht auf den "weißen, bezaubernden Busen" seiner Sofanachbarin, "der so niedlich mit Fleisch überkleidet war, dass ihre Brüste, gerundet und fest, sich ohne Schnürbrust aufrecht hielten».

Wenn sich ein Beziehungsgeschehen so umständelos darstellt, dann nennt man es Literatur. Und aufs Ganze gesehen hat die Literatur wohl nie von etwas anderem erzählt als von neapolitanischem Biskuit und weißen, bezaubernden Busen. Dass der Briefroman "Fanny Hill» über zwei Jahrhunderte auf dem Index stand, kann nur am süditalienischen Feingebäck gelegen haben, dessen Unbedenklichkeit lange nicht erwiesen war.

Andererseits scheint die Sache mit dem Auskleiden und Entkleiden ja nicht schon dadurch abgetan, dass man sich nach dem Dampfbad beim Barfußparcours auf Rindenmulch und Zapfensplit begegnet. Es gibt eine professionelle Nacktheit, die auch mit Verwöhnportionen Biskuit nicht mehr zu entnüchtern wäre. Und niemand im Nudistencamp, der sich dafür interessierte, ob er erst die Hose ausgezogen hat oder doch erst das Hemd.

Nur dem Maler darf nie die Lust vergehen. Immer muss er ein bisschen schwärmen und überschwänglich tun und Busen mit niedlichem Fleisch überkleiden und venusgut drauf sein, auch wenn es die reine Routine ist und das Modell so gar kein Geschick zeigt, die Naturnackte zu spielen. Was Wunder, dass es einem im Damenflügel des Museums, bei den ungezählten Toilettenverrichtungen, die die Kunstgeschichte bewahrt, zuweilen zumute ist wie

\section{KARGER}

Fax +497614520714

Information@Karger.de

www.karger.com (c) 2008 S. Karger GmbH, Freiburg
Müller 
bei der Vorsorgeuntersuchung. Man muss sich deshalb nicht gleich wie ein Banause vorkommen. Am Abend vor den Häufchen Buntwäsche, Feinwäsche, Kochwäsche sind die Kunstbusen in der Galerie schon wieder vergessen, und es ist, wenn man die Leggins erst einmal aus hat, bequem Zeit, darüber nachzudenken, was das eigene Entkleidungstheater dem offiziellen Spielplan voraus hat.

Es kann ja nicht falsch sein, wenn man an all den famosen Badenden draußen und drinnen, an den gut beleumundeten Wannenliegerinnen, Wannensteherinnen, Wasserschütterinnen, Schwammhalterinnen, Kammschwingerinnen und Spiegelguckerinnen ein wenig Maß nimmt. Sie tun doch, was sie tun, aus keinem anderen Grund und zu keinem anderen Behuf, als uns zu zeigen, wie man so etwas tut, mit Anstand genießend, sittsam sinnlich, ästhetisch wohlgefällig - kurz, wie man Nutzen und Anmut zum Ruhme der Spezies und der Kunst vereint. Denken wir nur an den Fall Magdalena. Büßerin soll sie sein, hat aber nichts am Leib. Der Maler Tizian lässt sie in den Himmel gucken, dass es aussieht, als sei dort oben ein großer, dezent beleuchteter Badezimmerspiegel montiert, der alles Büßen in artiges Staunen verwandelt.

Nun wissen wir nicht, was es alles zu büßen gibt. Der Mensch ist allemal schuldig und in hohem Masse schuldbedroht, wenn er erst einmal die Kleider abgelegt hat. Magdalena wird dabei sorgsam vorgegangen sein, mit Umsicht die Leibwäsche gefaltet, sortiert und zur Wiederverwendung zusammengelegt haben. Dass außerhalb des Bildes noch unschöne Portionen aus Seide, Baumwolle oder Microfaser herumliegen, ist nicht anzunehmen. Dagegen spricht schon die subtile Pflege des Haupthaars, dessen Fülle hier nun wirklich einmal als Tracht zu beschreiben wäre. Die blonden Locken sind so lang gewachsen, dass sie sich zur monu- mentalen Haubenfrisur aufstecken ließen. Aber Magdalena trägt sie offen und schlingt und wickelt sie derart geschickt um den Leib, dass sie sich wie ein Bußgewand um die Nacktheit schmiegen - und nur den niedlich mit Fleisch überkleideten Busen frei lassen. Man sieht schon, worauf die Kunst hinaus will. Und das Salbgefäß, an dem die Kundigen die Bibelfrau erkennen, ist nichts anderes als ein Döschen für das neapolitanische Biskuit, das der junge Genueser mitgebracht hat.

Was also wäre zu lernen? Nichts weniger als Ordnung. Immer muss die Kunst Ordnung halten, immer muss sie vorführen, wie man sich richtig verhält ohne Schutzkleidung. In welcher Reihenfolge man beim idealen Stoffabwurf vorgeht, ob erst das Hemd aufzuknöpfen oder erst der Gürtel aus den Schlaufen zu ziehen ist. Wie man sich dann aufstellt vor Zuber, Becken, Bottich, Wanne und die Haare derart um die Blöße windet, dass immer noch ein bisschen Blöße bloß bleibt. Immer muss die Kunst die Körper vorschriftsmäßig entkleiden und die Busen niedlich mit Fleisch bekleiden. Dazu ist die Kunst da, dass unsereiner die Altsocken nicht irgendwo im Vestibül entsorgt.

Und das eben unterscheidet das Leben von der Kunst, dass man nie sicher sein kann und auf alles gefasst sein sollte. Jahrelang landeten die Kleinteile, die vom Tag geblieben waren, auf dem breiten Rücken des Fernsehapparats. Und wenn dann doch einmal die Spätnachrichten angeknipst wurden, dann war es wie eine feine Schabracke auf der Stirn von Tom Buhrow, und es wurde einem ganz schäfchenwohl. Mit einem Mal ist die Sicht frei. Und wir wissen nicht, ob es am neuen Wäschepuff oder am letzten Museumsbesuch liegt. Jedenfalls haben wir uns insgeheim geschworen, erst wieder neapolitanisches Biskuit mitzubringen, wenn sich der Büstenhalter in der Zimmerpalme verknotet.

Hans-Joachim Müller

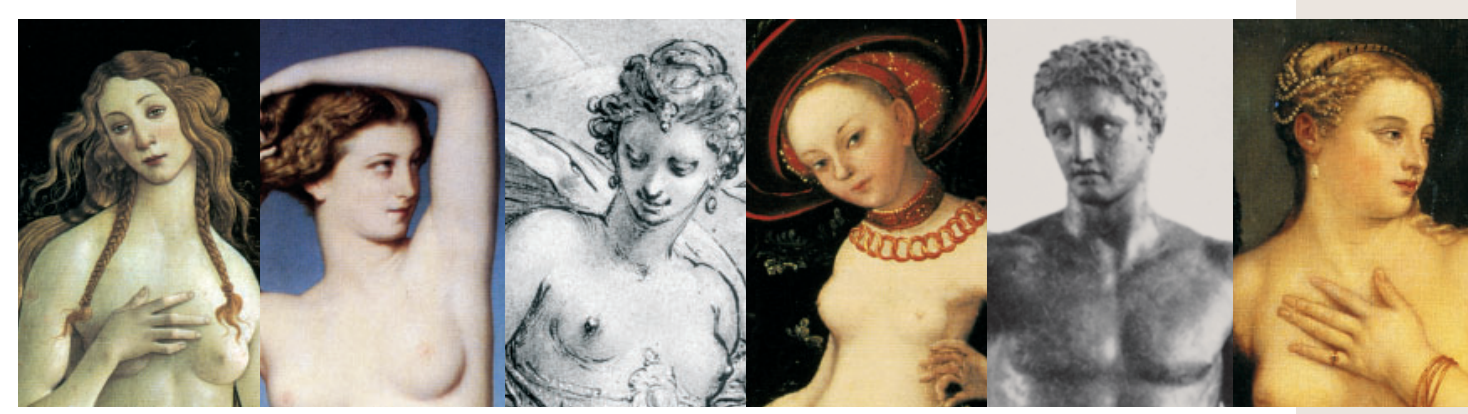

